\title{
XRD and SEM studies of reactively deposited tin oxide thin films
}

\author{
JOHNY T ABRAHAM*, PETER KOSHY, V K VAIDYAN*, \\ P S MUKHERJEE, P GURUSWAMY and L PRASANNA KUMARI \\ Regional Research Laboratory CSIR, Pappanamcode, Trivandrum 695019, India \\ * Department of Physics, University of Kerala, Kariavattom, Trivandrum 695 581, India \\ MS received 26 October 1994; revised 10 July 1995
}

\begin{abstract}
Stoichiometric polycrystalline tin oxide thin films were deposited by the reactive evaporation of tin and the $\mathrm{SnO}_{2}$ formation was found to be strongly dependent on the deposition parameters. The preferred orientation of the $\mathrm{SnO}_{2}$ films deposited on different substrates was varying due to the dislocation defects arising during the thin film formation. The X-ray diffraction (XRD) studies identified a tetragonal structure while the scanning electron microscopic (SEM) studies revealed a polycrystalline surface for the $\mathrm{SnO}_{2}$ films reactively deposited.
\end{abstract}

Keywords. Tin oxide; reactive evaporation; tetragonal; dislocation defects; recrystallization.

\section{Introduction}

Tin oxide thin films find applications in several technological areas, most notably as transparent conductors, spectrally selective coatings and gas-sensing elements (Chopra et al 1983). Thin films of $\mathrm{SnO}_{2}$ have been obtained by several methods like reactive evaporation, chemical vapour deposition and sputtering (Leja et al 1979; Muranaka et al 1981; Cavicchi et al 1992; Zhu et al 1993). The chemical vapour deposition process of tin oxide, although inexpensive, is being substituted by physical vapour deposition process, which is more controllable, leading to thin films of better purity and properties. In the present study, the reactive evaporation technique was made use of in preparing $\mathrm{SnO}_{2}$ thin films and the effect of deposition parameters is studied in detail.

\section{Experimental}

Thin films of tin oxides were prepared by the reactive evaporation of tin. The vacuum chamber was evacuated to about $10^{-5}$ torr before deposition and oxygen gas was admitted through a needle valve into the chamber until the required pressure was reached. Tin was evaporated by the resistive heating of tin granules with a constant deposition rate of about $0.3 \mathrm{~nm} / \mathrm{s}$, otherwise mentioned in the text. The deposition rate was monitored with a quartz crystal oscillator which was calibrated to measure the thickness of the film on the substrate. The substrate temperature was measured with a chromel-alumel thermocouple which was attached to one of the substrates. Thin films were deposited on glass and alumina substrates located about $18 \mathrm{~cm}$ from the source and the thickness ranged from 150 to $450 \mathrm{~nm}$. Surface characterization studies were carried out using a Philips PW1701 X-ray diffractometer and a JEOL 35C scanning electron microscope. 


\section{Results and discussion}

\section{$3.1 X R D$ studies}

To study the influence of oxygen partial pressure in the formation of $\mathrm{SnO}_{2}$, films were deposited at varying oxygen partial pressures. Table 1 gives the measured X-ray parameters and the identified surface phases of the films deposited at an oxygen partial pressure of $3 \times 10^{-4}(\mathrm{~S} 1), 3 \times 10^{-3}(\mathrm{~S} 2)$ and $10^{-2}$ torr (S3) at a substrate temperature of $823 \mathrm{~K}$. It is clear from the table that pure $\mathrm{SnO}_{2}$ was formed at an oxygen partial pressure of $3 \times 10^{-3}$ torr. Polycrystalline $\mathrm{SnO}_{2}$ films exhibited a tetragonal structure and a preferred orientation along the (101) plane. Other co-existing $\mathrm{SnO}_{2}$ phases were of $(110),(200)$ and (211) orientations. At an oxygen partial pressure of $3 \times 10^{-4}$ torr, $\mathrm{Sn}$ and $\mathrm{SnO}$ phases were found to co-exist with the $\mathrm{SnO}_{2}$ phases. This may be due to the lack of sufficient oxygen in the reacting zone. Again, at an oxygen partial pressure of $10^{-2}$ torr, where the percentage of oxygen was higher, we could not find any $\mathrm{SnO}_{2}$ phases, instead $\beta$-Sn and $\beta$-SnO phases were present. At this partial pressure of oxygen torr, the mean free path of evaporated $\mathrm{Sn}$ atoms decreases due to the collision with the oxygen atoms. This reduces the energy of $\mathrm{Sn}$ atoms and the formation of $\mathrm{SnO}_{2}$ molecules resulting in a $\mathrm{Sn} / \mathrm{SnO}_{x}(x<2)$ phase. The free energy of formation of the $\mathrm{SnO}$ and $\mathrm{SnO}_{2}$ molecules are 61 and $122 \mathrm{kcal} / \mathrm{mol}$, respectively.

Since an oxygen partial pressure of $3 \times 10^{-3}$ torr was found to be favoured for the formation of $\mathrm{SnO}_{2}$ films from the above results, $\mathrm{SnO}_{2}$ films were deposited at varying substrate temperatures of 373 (S4), 573 (S5), 773 (S6) and $823 \mathrm{~K}$ (S7). Table 2 presents the measured X-ray parameters and the identified surface phases. The data shows that the thin films were amorphous at lower substrate temperatures and polycrystalline at higher temperatures. Amorphous film formation at low temperature may perhaps be due to the low surface mobility of the adsorbed particles so that the disordered state is

Table 1. XRD data and phase identification of reactively deposited thin films at different oxygen partial pressures.

\begin{tabular}{|c|c|c|c|c|}
\hline $\begin{array}{l}\text { Sample } \\
\text { No. }\end{array}$ & $\begin{array}{c}2 \Theta \\
\text { (degree) }\end{array}$ & $\begin{array}{c}d \\
(\mathrm{~nm})\end{array}$ & $\begin{array}{l}I / I_{0} \\
(\%)\end{array}$ & Identification \\
\hline & $26 \cdot 7$ & 0.3338 & 7 & $\mathrm{SnO}_{2}(110)$ \\
\hline & $30 \cdot 7$ & 0.2912 & 100 & $\beta-\operatorname{Sn}(200)$ \\
\hline & $32 \cdot 1$ & 0.2788 & 76 & $\beta-\operatorname{SnO}(004)$ \\
\hline $\mathbf{S 1}$ & 33.9 & 0.2644 & 4 & $\mathrm{SnO}_{2}(101)$ \\
\hline \multirow[t]{4}{*}{$\left(3 \times 10^{-4}\right.$ torr $)$} & 43.9 & $0-2061$ & 20 & $\beta-\operatorname{Sn}(220)$ \\
\hline & 44.9 & 0.2018 & 39 & $\beta-\operatorname{Sn}(211)$ \\
\hline & $55 \cdot 4$ & $0 \cdot 1658$ & 6 & $\beta-\operatorname{Sn}(301)$ \\
\hline & $26 \cdot 7$ & 0.3338 & 59 & $\mathrm{SnO}_{2}(110)$ \\
\hline $\mathbf{S 2}$ & 33.9 & 0.2644 & 100 & $\mathrm{SnO}_{2}(101)$ \\
\hline \multirow{4}{*}{$\left(3 \times 10^{-3}\right.$ torr $)$} & 37.9 & 0.2373 & 27 & $\mathrm{SnO}_{2}(200)$ \\
\hline & 51.9 & 0.1761 & 65 & $\mathrm{SnO}_{2}(211)$ \\
\hline & $30 \cdot 6$ & 0.2921 & 100 & $\beta-\mathrm{SnO}(-)$ \\
\hline & $32 \cdot 1$ & 0.2788 & 52 & $\beta-\mathrm{SnO}(004)$ \\
\hline S3 & 43.9 & $0 \cdot 2061$ & 12 & $\beta-\operatorname{Sn}(220)$ \\
\hline \multirow[t]{2}{*}{$\left(10^{-2}\right.$ torr $)$} & 44.9 & $0 \cdot 2018$ & 24 & $\beta-\operatorname{Sn}(211)$ \\
\hline & 55.4 & 0.1658 & 4 & $\beta-\operatorname{Sn}(301)$ \\
\hline
\end{tabular}


Table 2. XRD data and phase identification of reactively deposited thin films at different substrate temperatures.

\begin{tabular}{|c|c|c|c|c|}
\hline $\begin{array}{l}\text { Sample } \\
\text { No. }\end{array}$ & $\begin{array}{c}2 \Theta \\
\text { (degree) }\end{array}$ & $\begin{array}{c}d \\
(\mathrm{~nm})\end{array}$ & $\begin{array}{l}I / I_{0} \\
(\%)\end{array}$ & Identification \\
\hline $\begin{array}{l}\text { S4 } \\
(373 K)\end{array}$ & - & - & - & Amorphous \\
\hline \multirow{5}{*}{$\begin{array}{l}\text { S5 } \\
(573 K)\end{array}$} & - & - & - & Amorphous \\
\hline & $30-0$ & 0.2978 & 54 & $\alpha-\operatorname{SnO}(101)$ \\
\hline & $30 \cdot 8$ & 0.2902 & 100 & $\beta-\operatorname{SnO}(101)$ \\
\hline & $32 \cdot 2$ & 0.2779 & 42 & $\mathrm{Sn}_{3} \mathrm{O}_{4}(112)$ \\
\hline & $33 \cdot 0$ & 0.2714 & 9 & $\mathrm{Sn}_{2} \mathrm{O}_{3}(200)$ \\
\hline S6 & $33 \cdot 9$ & 0.2636 & 4 & $\mathrm{SnO}_{2}(101)$ \\
\hline \multirow[t]{5}{*}{$(773 \mathrm{~K})$} & $37 \cdot 4$ & $0 \cdot 2404$ & 8 & $\alpha-\operatorname{SnO}(002)$ \\
\hline & $44 \cdot 1$ & 0.2053 & 14 & $\alpha-\operatorname{SnO}(102)$ \\
\hline & $45 \cdot 1$ & 022010 & 20 & $\mathrm{Sn}_{2} \mathrm{O}_{3}(131)$ \\
\hline & $50 \cdot 9$ & $0 \cdot 1793$ & 9 & $\alpha-\operatorname{SnO}(112)$ \\
\hline & $26 \cdot 7$ & $0 \cdot 3338$ & 59 & $\mathrm{SnO}_{2}(110)$ \\
\hline S7 & $33 \cdot 9$ & $0 \cdot 2644$ & 100 & $\mathrm{SnO}_{2}(101)$ \\
\hline \multirow[t]{2}{*}{$(823 \mathrm{~K})$} & 37.9 & $0 \cdot 2373$ & 27 & $\mathrm{SnO}_{2}(200)$ \\
\hline & 51.9 & 0.1761 & 65 & $\mathrm{SnO}_{2}(211)$ \\
\hline
\end{tabular}

frozen before the particles are able to reach the most preferred energetic sites corresponding to their respective crystallographic structures.

Further, the data in table 2 shows that though $\mathrm{SnO}_{2}$ has formed at a substrate temperature of $773 \mathrm{~K}$, other phases of tin were also found to co-exist. By increasing the substrate temperature to $823 \mathrm{~K}$, the formation of $\mathrm{SnO}_{2}$ was found to be complete.

To study the influence of substrate surface on the deposited film structure, $\mathrm{SnO}_{2}$ films were also deposited on a polycrystalline alumina surface at a substrate temperature of $823 \mathrm{~K}$ and an oxygen partial pressure of $3 \times 10^{-3}$ torr. Table 3 gives the calculated X-ray parameters corresponding to the identified $\mathrm{SnO}_{2}$ and $\mathrm{Al}_{2} \mathrm{O}_{3}$ phases. From the data it can be seen that though polycrystalline $\mathrm{SnO}_{2}$ was formed, the preferred orientation of the $\mathrm{SnO}_{2}$ films deposited on alumina shows a tendency to orient in the (110) plane with increasing thickness.

As per the thin film formation mechanism (Volmer and Weber 1925), film growth usually takes place first by nucleation. followed by the growth of nuclei and later by their coalescence. The nuclei growing on a substrate may have various crystallographic orientations for various growth conditions. It has been established that when two islands which are of different sizes and crystallographic orientations, coalesce, the resultant crystallite assumes, as a rule, the orientation of the larger one.

Electron-optical examinations of fcc metals by the moire technique (Eckertova 1986) have revealed that there are almost no defects in separate nuclei and that they arise only after the coalescence process begins. The most frequent defects are dislocations, which arise at the boundary of two crystal regions that are somewhat angularly displaced with respect to each other. Dislocations are also formed at the boundary between the thin film and substrate surface owing to the difference in their crystal lattice. And to eliminate the difference in orientation, the islands can move or rotate somewhat to eliminate the difference in orientation. Moreover, as per the concepts of thin film 
Table 3. XRD data and phase identification of tin oxide thin films reactively deposited on alumina substrate.

\begin{tabular}{lcccl}
\hline $\begin{array}{l}\text { Sample } \\
\text { No. }\end{array}$ & $\begin{array}{c}2 \Theta \\
\text { (degree) }\end{array}$ & $\begin{array}{c}d \\
(\mathrm{~nm})\end{array}$ & $\begin{array}{l}I / I_{0} \\
(\%)\end{array}$ & Identification \\
\hline & 26.7 & 0.3338 & 14 & $\mathrm{SnO}_{2}(110)$ \\
& 33.9 & 0.2644 & 13 & $\mathrm{SnO}_{2}(101)$ \\
S8 & 35.2 & 0.2549 & 95 & $\mathrm{Al}_{2} \mathrm{O}_{3}(103)$ \\
$(200 \mathrm{~nm})$ & 37.7 & 0.2386 & 27 & $\mathrm{Al}_{2} \mathrm{O}_{3}(200)$ \\
& 43.4 & 0.2084 & 100 & $\mathrm{Al}_{2} \mathrm{O}_{3}(202)$ \\
& 51.9 & 0.1758 & 7 & $\mathrm{SnO}_{2}(211)$ \\
& 52.7 & 0.1736 & 23 & $\mathrm{Al}_{2} \mathrm{O}_{3}(403)$ \\
& 57.7 & 0.1597 & 98 & $\mathrm{Al}_{2} \mathrm{O}_{3}(203)$ \\
& 26.6 & 0.3351 & 31 & $\mathrm{SnO}_{2}(110)$ \\
S9 & 33.9 & 0.2644 & 17 & $\mathrm{SnO}_{2}(101)$ \\
$(360 \mathrm{~nm})$ & 35.2 & 0.2549 & 84 & $\mathrm{Al}_{2} \mathrm{O}_{3}(103)$ \\
& 37.7 & 0.2386 & 27 & $\mathrm{Al}_{2} \mathrm{O}_{3}(200)$ \\
& 43.4 & 0.2084 & 100 & $\mathrm{Al}_{2} \mathrm{O}_{3}(202)$ \\
& 51.8 & 0.1764 & 10 & $\mathrm{SnO}_{2}(211)$ \\
& 52.7 & 0.1736 & 43 & $\mathrm{Al}_{2} \mathrm{O}_{3}(403)$ \\
& 57.7 & 0.1597 & 98 & $\mathrm{Al}_{2} \mathrm{O}_{3}(203)$ \\
\hline
\end{tabular}

formation (Maissel and Glang 1970; Eckertova 1986), an increase in substrate temperature can stimulate oriented overgrowth facilitating recrystallization. Any of the above mentioned lattice misfits must have taken place in the case of $\mathrm{SnO}_{2}$ films deposited on the alumina substrate at greater thickness. So, the $\mathrm{SnO}_{2}$ islands might have rotated or moved to eliminate this dislocation. And, in this process, the islands with (110) texture might have grown in prominence compared to the (101) texture.

In our further studies, it was found that the preferred orientation of the $\mathrm{SnO}_{2}$ films deposited on the polycrystalline quartz substrates was also along the (110) plane as in the case of alumina substrates, while it was only along the (101) plane even for a $400 \mathrm{~nm}$ thick $\mathrm{SnO}_{2}$ films deposited on glass substrates.

The influence of rate of evaporation on the $\mathrm{SnO}_{2}$ film formation was also studied. Under the optimum conditions for the $\mathrm{SnO}_{2}$ film formation, $\mathrm{SnO}_{2}$ films were reactively deposited at a rate of $1 \mathrm{~nm} / \mathrm{s}$. Though the XRD analysis identified a well defined polycrystalline $\mathrm{SnO}_{2}$ film, trace amounts of $\beta-\mathrm{Sn}, \alpha-\mathrm{SnO}$ and $\beta-\mathrm{SnO}$ were also found. Such a mixed state of $\mathrm{Sn}, \mathrm{SnO}$ and $\mathrm{SnO}_{2}$ was found when the source-substrate distance was reduced to $9 \mathrm{~cm}$. So, a very short distance or a faster rate of deposition results in an incomplete reaction in which the unreacted species are incorporated into the films.

\subsection{SEM studies}

The scanning electron micrographs of the reactively deposited $\mathrm{SnO}_{2}$ films are shown in figure 1. Figure 1( $a$ and $b$ ) depicts the morphology of film deposited on glass at a substrate temperature of $373 \mathrm{~K}$ at an oxygen partial pressure of $3 \times 10^{-3}$ torr. The surface morphology of the $\mathrm{SnO}_{2}$ films deposited at a substrate temperature of $823 \mathrm{~K}$ and an oxygen partial pressure of $3 \times 10^{-3}$ torr on glass and alumina substrates for thickness 200 and $360 \mathrm{~nm}$, are shown in figure 1 (c and d) and figure 1 (e and f), 

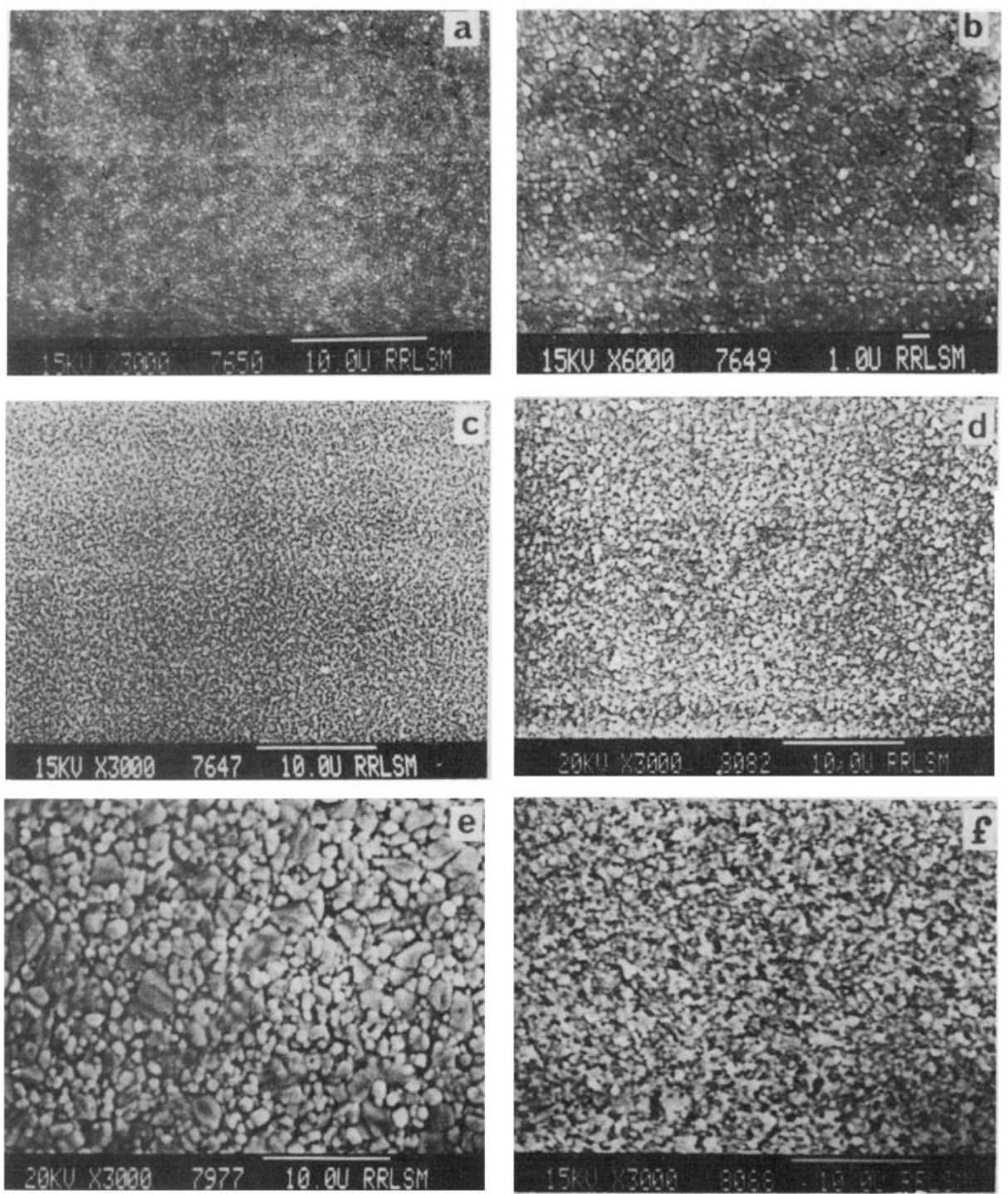

Figure 1. SEM of tin oxide thin films (a, b) of thickness $200 \mathrm{~nm}$ deposited on glass at a substrate temperature of $373 \mathrm{~K}$; (c, d) of thickness: 200 and $360 \mathrm{~nm}$, respectively, deposited on glass at a substrate temperature of $823 \mathrm{~K}$; and (e, f) of thickness 200 and $360 \mathrm{~nm}$, respectively, deposited on alumina at a substrate temperature of $823 \mathrm{~K}$.

respectively. Films deposited at low substrate temperatures reveal an amorphous surface texture with microcracks throughout the entire surface of the film (figure 1( $a$ and $b)$ ). Small and bright spots can also be seen distributed almost uniformly over the surface. These spots may be the nucleation centres. Figure l(c) exhibits an ultrafine potycrystalline structure for the films deposited on glass, whereas, figure 1(e) displays almost uniform spreading of a lot of islands on the background of a polycrystalline alumina surface. These islands may be due to the preferred nucleation of the $\mathrm{SnO}_{2}$ molecules in the cavities between the grain boundaries of the alumina 
surface. When these films grow in thickness, a more textured polycrystalline surface could be seen with an increased grain size (figure $1(\mathrm{~d}$ and $\mathrm{f})$ ). In the case of films deposited on alumina substrates, figure 1 ( $e$ and $f$ ), with the increase in thickness the $\mathrm{SnO}_{2}$ film covers the entire substrate surface as is evidenced by the disappearance of the polycrystalline background of alumina substrate surface and the film growth also seems to be more coagulated. Moreover, figure 1 ( $d$ and f) exhibit a coarse and smooth surface, respectively, which may be due to the preferred orientation of the polycrystalline surface in the (101) and (110) planes, respectively.

\section{Conclusions}

The structure of the $\mathrm{SnO}_{2}$ films was found to strongly depend on the deposition parameters. Tin oxide films were formed at an oxygen partial pressure of $3 \times 10^{-3}$ torr, substrate temperature of $823 \mathrm{~K}$, a source-substrate distance of $18 \mathrm{~cm}$ and at an evaporation rate of $0.3 \mathrm{~nm} / \mathrm{s}$. The as-deposited films were polycrystalline and exhibited a tetragonal structure. The preferred orientation of the $\mathrm{SnO}_{2}$ films deposited on glass substrate was along the (101) direction, while it was along the (110) direction for films deposited on alumina substrate. And, the variation in the orientation of the films was due to the recrystallization that had occurred in the case of films deposited on alumina substrate, so as to minimize the dislocation defects arising during the formation of the thin films.

\section{References}

Cavicchi R E, Semancik S, Antonik M D and Lad R J 1992 Appl. Phys. Lett. 611921

Chopra K L, Major S and Pandya D K 1983 Thin Solid Films 1021

Eckertova L 1986 in Physics of thin films (New York: Plenum Press)

Leja E, Korecki J, Krop K and Toll K 1979 J. Phys. 40408

Maissel L I and Glang R (eds) 1970 in Handbook of thin film technology (New York: McGraw Hill)

Muranaka S, Bando Y and Takada T 1981 Thin Solid Films 8611

Uen T M, Huang K F, Chen M S and Gou Y S 1988 Thin Solid Films 15869

Volmer M and Weber A 1925 Z. Phys. Chem. 119277

Zhu Y, Lu H, Lu Y and Pan X 1993 Thin Solid Films 22482 